\title{
Green economy in the world and in Russia: preconditions and prospects
}

\author{
Elvira Karieva ${ }^{1}$, Liliya Akhmetshina ${ }^{2, *}$ and Angela Mottaeva ${ }^{3}$ \\ ${ }^{1}$ Russian presidential Academy of national economy and public administration Perm branch, 10, \\ Gagarin, 614060, Perm, Russia \\ ${ }^{2}$ Financial University under the Government of the Russian Federation, 49, Leningradsky, 125993, \\ Moscow, Russia \\ ${ }^{3}$ Moscow State University of Civil Engineering, 26, Yaroslavskoye Shosse, 109377, Moscow, Russia
}

\begin{abstract}
A green economy supports the conservation of resources and reduces negative impacts on nature. The growth in the quality of human life "coexists" with the growth of natural capital, which ensures green growth. The aim of the study is to assess the state and substantiate the need for the development of a green economy in the world and in Russia in order to ensure intensification of efforts in the field of environmental protection, taking into account the positive impact on the development of national economies and the solution of social problems. The study made it possible to analyze the existing environmental problems and their impact on national economies, identify the prerequisites for the emergence of green technologies in the economy and the prospects for their implementation in the world and in Russia. As a result of the study, the initiatives of specialists for the development of the green economy in the world are identified, the provisions of the green course for the development of the Russian economy are presented.
\end{abstract}

\section{Introduction}

Nowadays, the global trend that determines the sustainability of the development of national economies is a change in the course of the traditional model of economic growth towards a green economy. The foundation for the development of a new green economy capable of investing natural and financial capital much more efficiently in the foreseeable future was laid in the UN Environment Program in 2009.

As part of a green economy initiative involving a large number of partners and experts from around the world, a global green new course was presented, which should help to overcome the social, economic and environmental consequences of the global financial crises, while addressing issues related to negative changes in the global climate caused by the problems of food, fuel and water resources.

In the United Nations Environment Program, the green economy is characterized as a resource efficient economy with low carbon emissions and in the interests of the whole society [1].

\footnotetext{
* Corresponding author: akhmetshinalg@mail.ru
} 
Existing studies reflect various aspects related to the formation and development of the green economy in the world and in Russia. However, based on consideration of world experience, the problems of green development in Russia require further study and development of applied aspects of the transition to a green economy. The circumstances noted above determined the relevance of the study.

\section{Materials and Methods}

The work was carried out on the basis of statistical data on the development of the green economy in Russia and the world, research materials by foreign and domestic authors. The study of various sources of information with the subsequent generalization of data, analytical and comparative methods were used as research methods.

Global trends in the global green economy are focused on improving energy efficiency and the introduction of renewable energy sources. In 2009, a Green Growth Declaration was signed by 34 countries, pledging the need to develop a Green Growth Strategy that calls for "change and innovation, such as new business models, work patterns, city planning or transport opportunities, that will become tools that drive green growth" [2].

It should be noted that the relationship between economic growth and the impact of changes in the global climate and the environment was first studied in the world in the 1990s by Nobel laureate W. Nordhaus, who developed a quantitative model describing this relationship.

W. Nordhaus began to study economic problems caused by climate change in the 1970s and proposed an "integrated valuation model" that described the correspondence of the total volume of natural resources used to a certain amount of greenhouse gas emissions that negatively affect the average air temperature, which, in turn, determines the factor corresponding to environmental damage. As a result, the total productivity of production factors decreases and, as a result, the welfare of the population worsens, economic growth and the development of human capital are suppressed.

The need for a transition to a green economy in the world is predetermined by the critical exacerbation of disparities between economic development and environmental degradation. The dynamics of world GDP from 1980 to 2019 testifies to its eight-fold increase over this period (Fig. 1). It should be noted that this growth indicates a global depletion of natural capital and degradation of ecosystems.

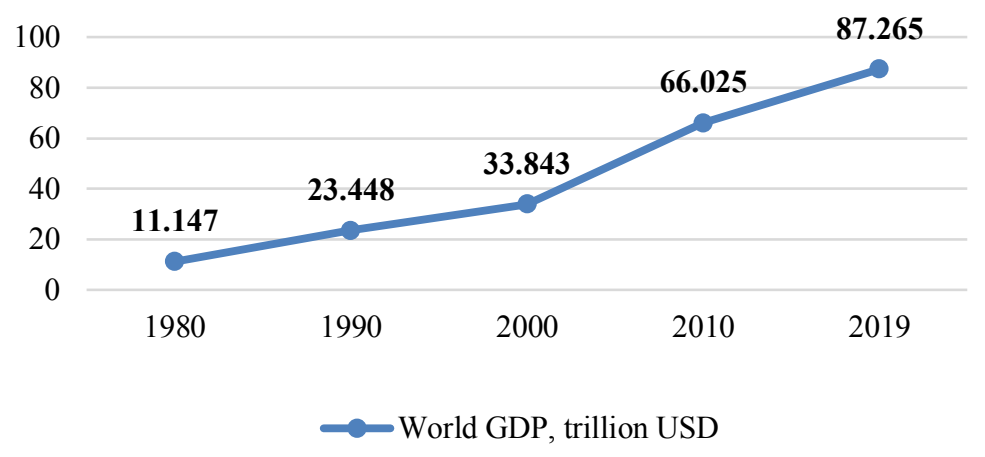

Fig. 1. Dynamics of world GDP in current prices according to the IMF, 1980-2019 [3].

The growth of environmental problems in the world is characterized by a growing shortage of fresh water and food, climate change, a decline in biodiversity and forests, and desertification. 
According to the UN Water Resources Report (2019), the supply of fresh water needed for drinking, growing food, and producing energy is decreasing, and by 2050, almost half of the world's population will not be able to have access to supplies of safe water. The specialists participating in the preparation of this report associate this with climate warming, a sharp increase in consumption, and pollution of water bodies.

It should be noted that, according to scientists, the largest volume of fresh water is consumed by agriculture - almost $70 \%$ of the total reserves. As noted in the report, with the growth of the world's population, the demand for agricultural production will increase and, as a result, the volume of water consumption will increase. According to a UN report, over the past century, water consumption has more than doubled the rate of population growth. At the same time, in May 2019, the total number of people living on Earth reached 7.7 billion, and this number continues to grow. According to UNESCO, by 2050, the global demand for food will increase by $70 \%$. In addition, according to expert estimates, by 2050 , global water consumption by agriculture (both irrigated and non-irrigated) will grow by about $19 \%$ [4].

According to UN forecasts, water consumption will grow by $10 \%$ from $4000 \mathrm{~km}^{3}$ in 2014 to $4100 \mathrm{~km}^{3}$ in 2025 and $4400 \mathrm{~km}^{3}$ in 2040 . In addition, due to chemical pollution, part of water resources annually falls out of the water cycle in nature in the form the socalled irrecoverable losses, which will also increase by almost $20 \%$ from $1450 \mathrm{~km}^{3}$ in 2014 to $1700 \mathrm{~km}^{3}$ in 2040 . It should be noted that in many developing countries, water losses amount to more than $30 \%$. For example, the leakage of water from urban water supply systems around the world is more than 32 billion $\mathrm{m}^{3}$ of drinking water, and only $10 \%$ of them are visible, the rest quietly and silently disappear under the ground.

In addition, according to the US Geological Survey, only $2.5 \%$ of the world's water resources, or about 35 million $\mathrm{km}^{3}$, are suitable for humans, of which $68.7 \%$ are glaciers and ice caps, and $30.1 \%$ are difficult to extract underground waters. Thus, only $1.2 \%$ of fresh water on the Earth's surface remains for man.

Besides, the distribution of water resources across the planet is uneven. It should be noted that Russia is in the group of countries with the richest water resources, holding 2nd place (Fig. 2).

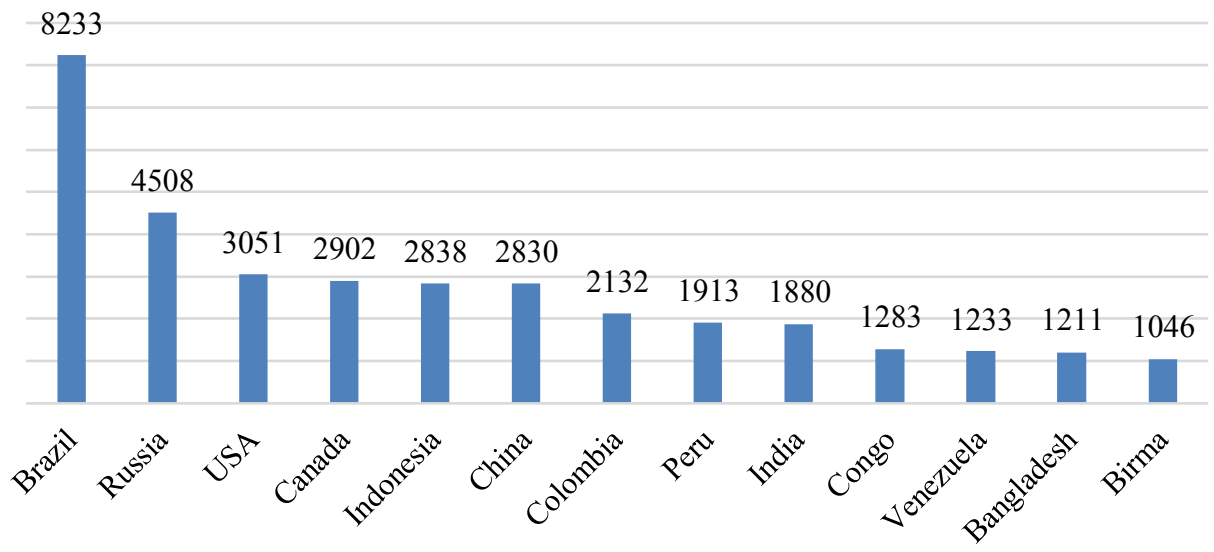

Availability of water resources, $\mathrm{km} 3$

Fig. 2. Countries of the world richest in water resources.

Despite the pessimistic forecasts, environmental scientists offer alternative options for the further development of events. For example, based on the results of computer 
simulations by specialists from the Massachusetts Institute of Technology, it is determined that the rightly chosen policy solutions aimed at combating climate change, such as the Paris Agreement of 2015, will reduce the negative impact of awaiting water scarcity on the world. Scientists have found that with the further adoption of such decisions by the world community in the future, it is possible to avoid a catastrophic water shortage for 60 million people in Asia by 2050.

In addition to ineffective use of water resources, a pressing environmental problem is also the reduction of forest area.

According to the results of the global assessment of the world's forests as of 2020 by the food and agriculture organization of the United Nations, since 1990, there have been losses of 178 million hectares of forests. The Global Forest Resources Assessment 2020 report indicates that faster rates of deforestation are being seen in Africa, where forest area declined by 3.9 million hectares annually from 2010 to 2020. The report also indicates that about a third of the land area or 4.06 billion hectares is covered with forest. More than half of all forest area, specifically $54 \%$, is located in five countries. It is noteworthy that Russia is in first place among the designated countries, having 815 million hectares of forests (Fig. 3). Brazil holds the second place with 497 million hectares, followed by Canada with 347 million hectares, the USA - 310 million hectares, and China with 220 million hectares.

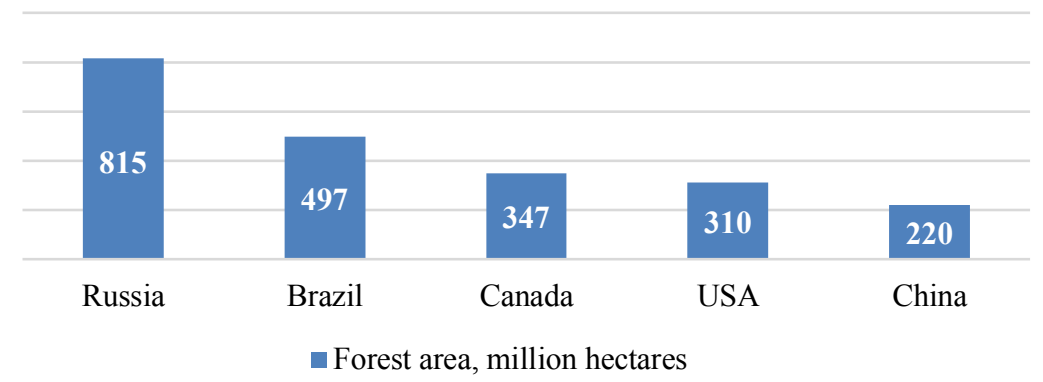

Fig. 3. Top 5 countries with the largest forest areas.

It should be noted that the main findings of the report indicate that forest loss has slowed. In the world over the past five years, the annual reduction of forests was 10 million hectares, while in the previous five-year period - 12 million hectares per year, and for the period 2005-2010, the annual reduction was 16 million hectares. According to experts, the largest deforestation in the past ten years was observed in Brazil, the Democratic Republic of the Congo and Indonesia. Conversely, an increase in forest area was recorded in China, Australia and Chile.

Among the positive aspects, the authors of the report note that 726 million hectares of world forests or $18 \%$ of their total area are under protection. In addition, this figure has increased by 191 million hectares over three decades.

Deforestation leads to serious consequences for the economy and production, and the ecological balance is disturbed. The negative impact is expressed in the disappearance of living organisms, desertification, formation of swamps, deterioration in the quality of air purification, violation of climate stability and an increase in the content of carbon dioxide in the air, which is one of the causes of global warming.

The forecasts of the Intergovernmental Panel on Climate Change (IPCC) indicate that by 2300 , the average global temperature will increase by 8.5 degrees compared to the period 1961-1990, taken as a reference point in paleoclimatic constructions, which will lead to active melting of continental glaciers and a sharp rise in the level of the World Ocean with all the ensuing consequences. 
Thus, it can be stated that the development of the world economy has contributed to the global environmental crisis.

\section{Results}

In turn, according to experts from the World Economic Forum (WEF) and the PricewaterhouseCoopers (PwC) consulting company, climate change and other environmental problems have a negative impact on world GDP. The experts' estimate indicates a moderate or strong dependence of the formation of world GDP "...on nature and what it gives", namely, 44 trillion dollars or almost half of world GDP.

According to experts, the spheres most dependent on nature are construction with a contribution to GDP of 4 trillion. dollars, agriculture with 2.5 trillion dollars, and food production with 1.4 trillion dollars, since in these industries, either the direct use of natural resources or a strong dependence on the ecosystem is necessary. For example, the need for fertile soil, clean water, pollination, a stable climate, etc.

According to WEF Managing Director Dominic Waughray, "natural losses simultaneously have a significant impact on all areas of business and are an immediate and non-linear risk to our future collective economic security" [5].

In these conditions, the green economy, which is part of nature and sets the task of managing the economy of nature, is becoming the main vector for the development of the world economy as a whole. It should be noted that the concept of green economy is aimed at maintaining and conserving natural resources and reducing the negative impact on nature.

Modern models of the green economy are reflected in the priorities of the practical activities of many states. In 2009, the countries of the Organization for Economic Cooperation and Development (OECD) adopted the Strategy for Environmentally Oriented Growth, or the so-called Green Growth, as a tool to overcome the financial and economic crisis for 2030-2050.

The first state to designate a green economy as a national development strategy is South Korea, which has risen to the ranks of the largest economies in the world from a poor country that has been in postwar devastation in less than 50 years. However, high rates of industrialization and urbanization have contributed to an intense increase in greenhouse gas emissions and pollution of the biosphere. At the beginning of the XXI century, it becomes evident that the past strategies that have led the country to success are no longer working. In 2008, Korea introduced a low-carbon green growth strategy, in which green technology projects account for about $2 \%$ of national GDP annually. Already in 2010, the country established the Global Green Growth Institute (GGGI), which provides consulting assistance to developing countries. Currently, 27 countries are members of this institution, in which \$ 524.6 million was spent on the development of the green economy in 2017.

The contribution of the green economy to the development of the economic complex of individual states, which concentrate the bulk of the capacities and investments in this area in 2009, was presented as follows. In the United States, the green economy produced goods and services worth more than $\$ 600$ billion, or $4.2 \%$ of GDP, and employment in this sector was estimated at 3 million people. In Japan, the green economy accounted for $3.4 \%$ of GDP and employed 1.5 million people. In the EU countries, this sector of the economy accounted for $2.5 \%$ of total GDP and employed more than 3.4 million people.

It should be noted that already in 2010, the green sector of the economy was estimated in the world at $\$ 2$ trillion, or $2.7 \%$ of world GDP. At the same time, the profit in this sector was $\$ 530$ billion, and employment - about 10 million people. China has established a global leadership position by focusing nearly $40 \%$ of global investment in the development of environmentally friendly energy. 
Already in 2016, according to the GreenTech-Atlas 2018 [3] presented by the German Ministry of the Environment, in which the analysis and calculations were carried out by the Roland Berger consulting company, the volume of the world market for green technologies amounted to 3.2 trillion euros. At the same time, the authors predict an average annual growth rate of $6.9 \%$ by 2025 , which will significantly exceed the rate of development of the world economy, and as a result, the market volume of green technologies will reach 5.9 trillion euros, including six segments or submarkets (Fig. 4).

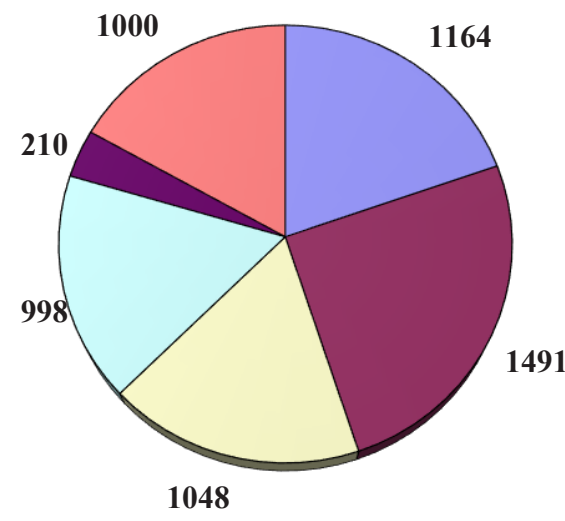

口Environmentally friendly production, accumulation and distribution of energy (RES, storage, Smart grid, etc.)

口Energy efficiency submarket

口Efficient use of raw materials and supplies (including the production of biological substitutes for fossil raw materials)

口Environmentally sustainable mobility (development of new transport technologies and biofuel production)

- "Circular" economy (waste management economics)

\section{口Environmentally sustainable water management (including various aspects of wastewater management)}

Fig. 4. Forecasted volumes of submarkets of the market of green technologies for 2025, billion euros.

According to the head of the Ministry of Natural Resources of Russia S. Donskoy at the opening of the second international exhibition and forum Ecotech in 2017, the global market for green technologies by 2020 will reach 4.5 trillion dollars.

It should be noted that the demand for green technologies in Russia was due to the active arrival of Western companies that have long integrated sustainable development into business strategies, in which the environmental aspect is the most important criterion in assessing efficiency.

In Russia, the relevance and need for the introduction and development of green economy technologies was noted in March 2012 in the report "Strategy 2020: A New Growth Model - New Social Policy" [6]. This report emphasized that the content of the federal policy in the field of environmental development of the country should be aimed at the strategy of green growth, providing for the integration of socio-economic and environmental development in the form of a green economy.

In 2013, the Declaration on the implementation of the principles of green economy in Russia was adopted, aimed at transforming economic activity in the following areas: improving the quality of life of the population based on creating a safe environment for health; high rates of development of industries that are strategic for the national economy; careful and rational use of natural resources in the interests of future generations; fulfillment of international environmental obligations by the country.

It should be noted that Russia does not currently occupy a significant position in the global process of developing the green economy. 
Since 2010, the American communications agency "Dual Citizen" has been compiling an index of the greenest national economies (Global Green Economy Index - GGEI), taking into account four factors: the quality of the environment and natural capital; markets and investments in the green sector; the position of the political leadership of the state and climate change; local industry strategy. According to the results of the assessment by this agency in 2018, Russia is in the 114th position (Fig. 5).

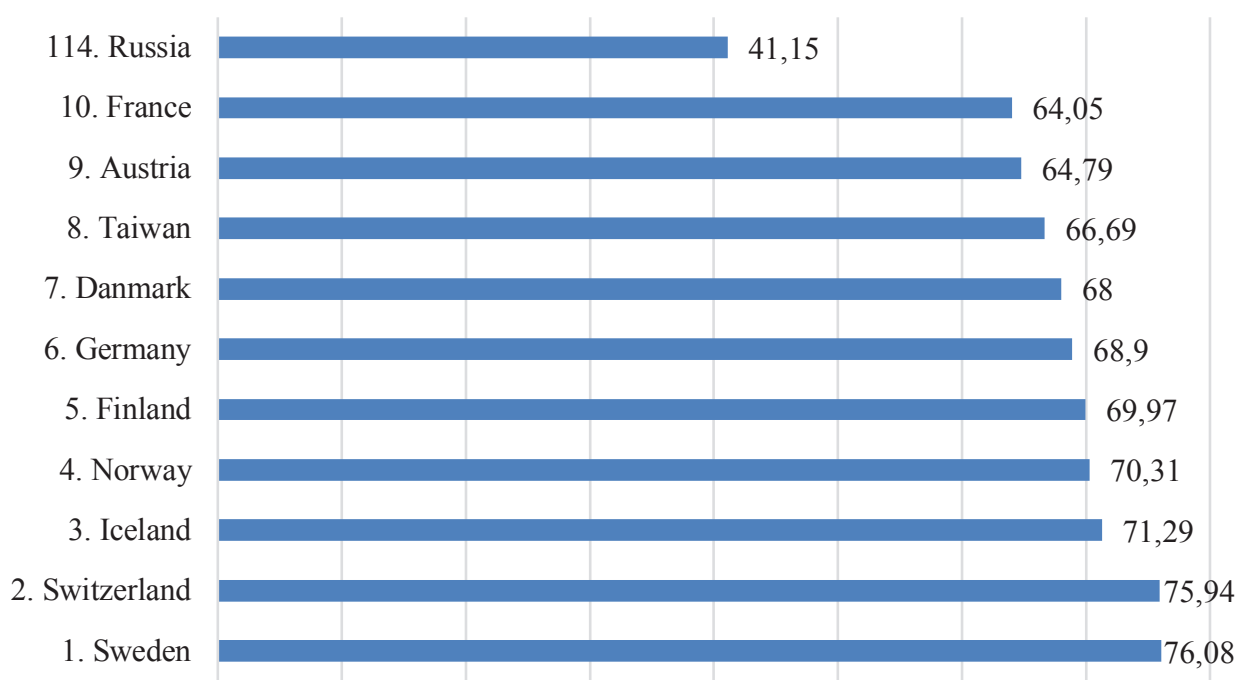

- Global Green Economy Index

Fig. 5. Rating of the Global Green Economy Index in the countries of the world (top 10), 2018.

Nevertheless, it should be noted that in 2020, the experts of Greenpeace and RANEPA developed a program for the green development of Russia for the period up to 2050, in which the main proposed goals are the achievement of a zero level of greenhouse gas emissions, $100 \%$ share of renewable energy sources in the energy balance, recycling at least $80 \%$ of waste. Within the framework of the designated goals, it is planned to achieve by 2030 an increase in the share of renewable energy sources (RES) in electricity production up to $20 \%$, in the transport industry and in the heating/cooling sector - up to $10 \%$; increasing the share of RES in all energy sectors to $100 \%$ by 2050 ; a decrease in the energy intensity of Russia's GDP by $40 \%$ by 2030 compared to 2007 , and then its decrease by 2050 to the world average value; reducing the volume of solid municipal waste generation per capita by $30 \%$ from the level of 2020 by 2030 and by $60 \%$ by 2050 ; ensuring the processing of generated waste at a level of at least $80 \%$; transition from the development of the remaining wild forests to intensive forestry on previously developed lands; ensuring full protection of forests and effective extinguishing of forest fires [7].

\section{Conclusions}

In modern conditions of development of national economies, a new model of economic development is gaining more and more importance, which does not violate the balance of economic, social and environmental interests. Given the scale of the serious negative consequences of the functioning of the current economic development model, the world is preparing for the transition to a new model of the green economy, which is inevitable. 
Therefore, many countries are preparing their strategies for the transition to this model, and the most developed have already taken practical steps in this area.

Thus, the urgency and need for the development of a green economy in the world and in Russia are focused primarily on intensifying efforts in the field of environmental protection, taking into account the economic action program, which has a significant positive impact on the development of national economies and the solution of social problems. For Russia, in particular, the implementation of the green economy strategy will contribute to the diversification of the economy, eliminating its dependence on fossil fuels, and creating new modern industries and new jobs.

\section{References}

1. The Global Green New Deal, http://greenlogic.by/content/files/GREENTRANSPORT/UNEP90_RUS.pdf

2. Green Growth Declaration, https://www.oecd.org/greengrowth/48634082.pdf

3. The global market for green technologies will grow to 5.9 trillion euros by 2025 , http://energy.esco.agency/rubriki-zhurnala/prognozy-i-analitika/1135/mirovoj-rynokzeljonyh-tehnologij-vyrastet-k-2025-godu-do-5-9-trln-evro

4. United Nations World Water Development Report (WWDR), http://www.unesco.org/new/en/natural-sciences/environment/water/wwap/

5. WEF Report on Global Risks 2020: Focus on Climate, http://www3.weforum.org/docs/WEF_New_Nature_Economy_Report_2020.pdf

6. Strategy 2020: New Growth Model - New Social Policy. Final report on the results of expert work on topical issues of Russia's socio-economic strategy for the period up to 2020 (Publishing house "Delo", RANEPA, Moscow, 2013)

7. Russia's green course, https://greenrecovery.ru/wpcontent/uploads/2020/09/gc_a4_006.pdf

8. S.N. Bobylev, World of a new economy 3, 90-96 (2017)

9. E.A. Borkova, Management consulting 5, 68-76 (2020)

10. Green economy and sustainable development goals for Russia: collective monograph (Faculty of Economics, Lomonosov Moscow State University, Moscow, 2019)

11. Global finances, http://global-finances.ru/vvp-mira-po-godam 